\title{
Anatrophic Nephrotomy as Nephron-Sparing Approach for Complete Removal of Intraparenchymal Renal Tumors
}

Marcos F. Dall'Oglio, Lucas Ballarotti, Carlo C. Passerotti, Davi V. Paluello, Jose Roberto Colombo Junior, Alexandre Crippa, Miguel Srougi

Urology Division, University of Sao Paulo Medical School, Sao Paulo, Brazil and Cancer Institute of Sao Paulo, Sao Paulo, Brazil

\section{ABSTRACT}

Objective: Partial nephrectomy for small kidney tumors has increased in the last decades, and the approach to non-palpable endophytic tumors became a challenge, with larger chances of positive margins or complications. The aim of this study is to describe an alternative nephron-sparing approach for small endophytic kidney tumors through anatrophic nephrotomy.

Patients and Methods: A retrospective analysis of patients undergoing partial nephrectomy at our institution was performed and the subjects with endophytic tumors treated with anatrophic nephrotomy were identified. Patient demographics, perioperative outcomes and oncological results were evaluated.

Results: Among the partial nephrectomies performed for intraparenchymal tumors between 06/2006 and 06/2010, ten patients were submitted to anatrophic nephrotomy. The mean patient age was 42 yrs, and the mean tumor size was 2.3 $\mathrm{cm}$. Mean warm ischemia time was $22.4 \mathrm{~min}$ and the histopathological analysis showed $80 \%$ of clear cell carcinomas. At a mean follow-up of 36 months, no significant creatinine changes or local or systemic recurrences were observed. Conclusion: The operative technique described is a safe and effective nephronsparing option for complete removal of endophytic renal tumors.

\section{ARTICLE INFO}

\section{Key words:}

Kidney neoplasms; nephrons; Urologic Surgical Procedures; Outcome Assessment (Health Care)

Int Braz J Urol. 2012; 38: 356-61

Submitted for publication: March 23, 2011

Accepted after revision: April 18, 2012

\section{INTRODUCTION}

With the development of imaging diagnosis techniques, and the higher number of requested exams, there has been a growth of the incidence of small renal tumors, and an increase of the indication of nephron-sparing surgery, with excellent oncological and functional outcomes (1). In the last years, the incidental lesions are responsible for more than $60 \%$ of kidney tumors and $80 \%$ of these are in stages I and II (2).
Nephron-sparing renal surgery has been increasingly used for small renal mass $(<4 \mathrm{~cm})$ and, in selected cases, up to $7 \mathrm{~cm}$ renal tumors with similar oncological outcomes compared to radical nephrectomy, (3-5) with small complication ratio (6). The 5-year recurrence-free survival is approximately $96 \%$ for lesions smaller than $4 \mathrm{~cm}$, and of 83\% for lesions from 4 to $7 \mathrm{~cm} \mathrm{(7).}$

However, renal occult tumors diagnosed by imaging techniques represent greater technical difficulties for localization and resection, and may 
increase the chances of complications (8) (Figures $1 \mathrm{~A}-\mathrm{C})$. To precisely locate the tumor during surgical resection, intraoperative ultrasound during the operation has been used successfully (9).

The objective of this study is to present an alternative surgical approach for the complete enucleation of endophytic tumors through anatrophic nephrotomy, avoiding radical nephrectomy.

\section{MATERIALS AND METHODS}

The authors performed a retrospective analysis of patients undergoing partial nephrectomy at their institution and all subjects with endophytic tumors treated with anatrophic nephrotomy were identified (Figures 2A-D). Patient demographics, perioperative, functional and on-

Figura 1 - (A-C) Intraparenchymal tumors.

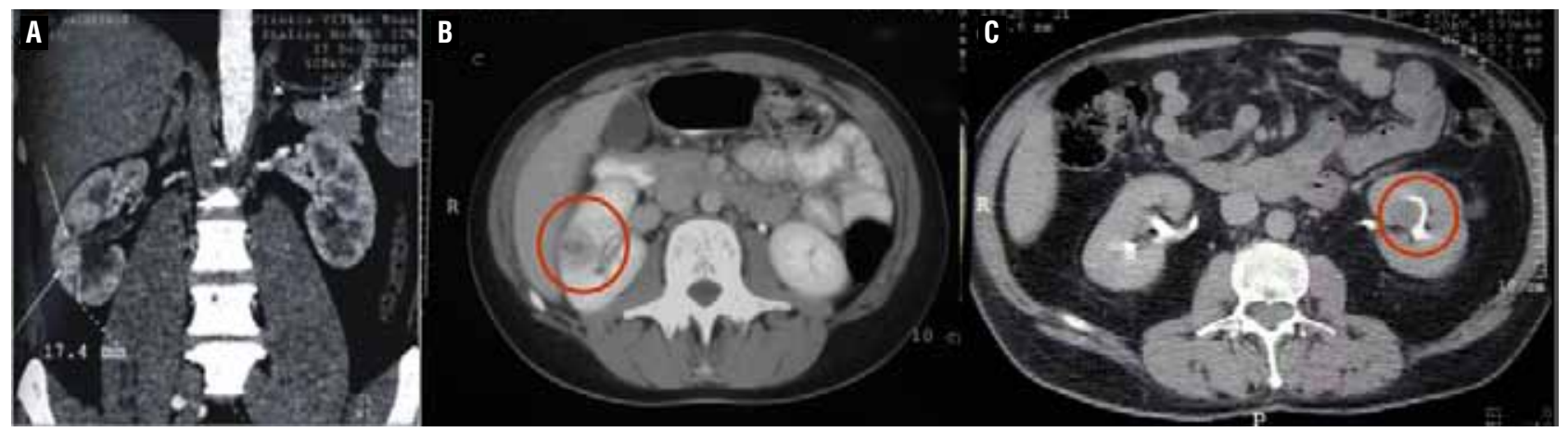

Figure 2 - (A) Identification of the tumor using ultrasound; (B) Brodel's vascular line incision and tumor identification; (C) Image after enucleation of the tumor ; (D) Renorrhaphy.
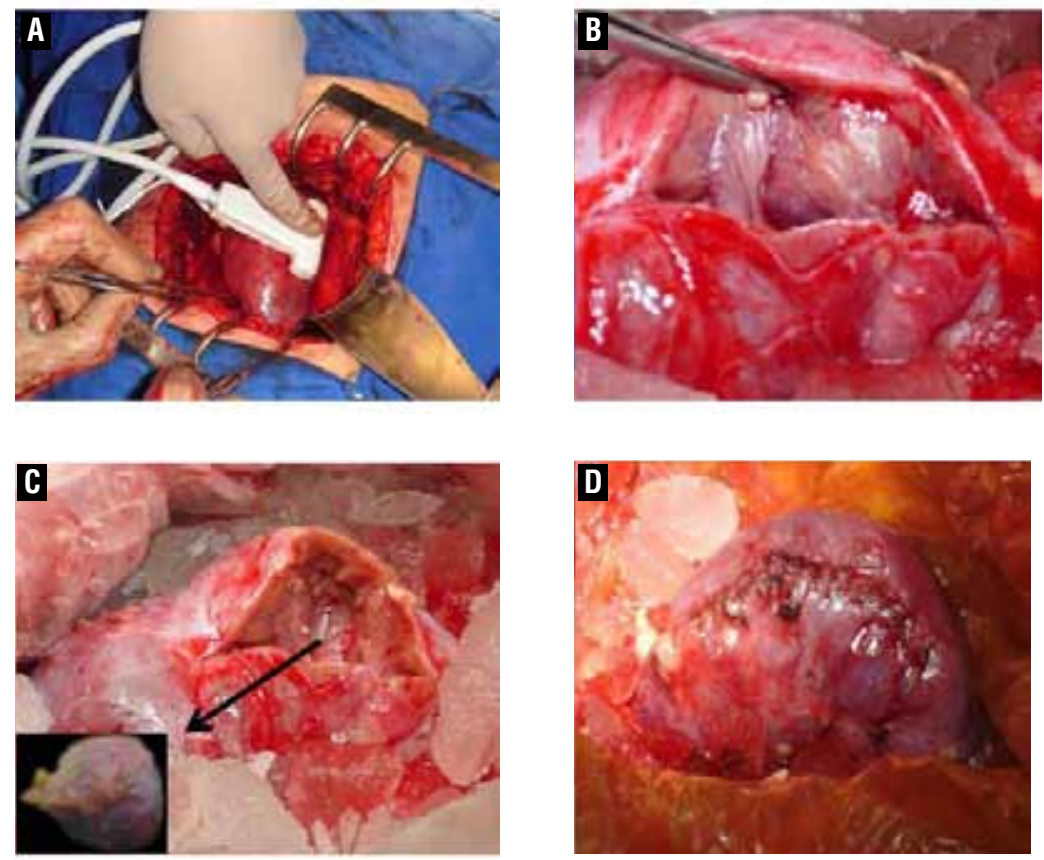
cologic results were evaluated. Among 554 renal tumors treated between 06/2006 and 06/2010, in 187 it was performed partial nephrectomy, and ten patients underwent partial nephrectomy through anatrophic nephrotomy.

The detailed operative technique is described below:

A) The access is made through either a flank or anterior subcostal incision; the kidney is dissected and exposed, and the renal artery and vein are repaired;

B) Ultrasound is used to identify the tumor borders and depth. Before renal artery clamping, it is infused intravenously $50 \mathrm{~mL}$ of mannitol $20 \%$ for nephron protection during warm ischemia. Ice is used to involve the kidney after clamping for $3 \mathrm{~min}$ before initiating the tumor resection, and in this case both artery and vein are clamped (Figure-2A);

C) Right after the renal artery clamping with a bulldog, the nephrotomy is performed along the Brodel's vascular line for the visualization of the tumor (Figure-2B). The tumor enucleation is then carried out using a combination of blunt and sharp dissection (Figure-2C). The surgical specimen is immediately sent to the histopathological laboratory in order to verify the margins during the renal reconstruction. The hemostasis is done through parenchymal stitches of 2.0-chromed catgut. Renorrhaphy is then performed with a running Vicryl ${ }^{\circledR} 0$ suture (Figure-2D);

D) A suction drain is placed surrounding the closed Gerota's fascia in all cases and the incision is closed.

\section{RESULTS}

Ten patients were evaluated. The mean age was 42 yrs (30-59), and nine were male. The mean tumor size was $2.3 \mathrm{~cm}(1.5-3.5)$, compared with $3.5+2.4 \mathrm{~cm}$ of all partial nephrectomies. Mean warm ischemia time was $22.4 \mathrm{~min}$ (15-30) (Table 1). The mean pre-operative serum creatinine was $0.88 \mathrm{mg} / \mathrm{dL}$, and the post-operative value was 0.94 $\mathrm{mg} / \mathrm{dL}$, measured two weeks after surgery.

Table 1 - Patient demographics, renal functional outcomes and warm ischemia time

\begin{tabular}{lccccc}
\hline Patient & Gender & Age (years) & Tumor size $(\mathrm{cm})$ & Tumor location & Ischemia Time (min) \\
\hline 1 & M & 46 & 1.5 & TM / RK & MP \\
2 & M & 34 & 1.7 & UP / LK & 25 \\
3 & M & 49 & 1.5 & MP / RK & 30 \\
4 & M & 30 & 2.7 & LP /LK & 24 \\
5 & M & 49 & 1.7 & MP / RK & 19 \\
6 & M & 59 & 2.0 & MP / LK & 25 \\
7 & M & 51 & 3.0 & LP / RK & 22 \\
9 & F & 39 & 3.5 & MP / RK & 28 \\
10 & M & 30 & 2.5 & LP / LK & 16 \\
\hline Mean & M & 32 & 3.0 & UP / LK & 15 \\
\hline
\end{tabular}

UP= Upper Pole; MP = Medium Third; LP = Lower Pole

RK= Right kidney; LK= Left kidney 
Table 2 - Pathological characteristics of kidney tumors

\begin{tabular}{lccccc}
\hline Patient & Histology* & Fuhrman grade & $\begin{array}{c}\text { Vascular } \\
\text { Invasion }\end{array}$ & $\begin{array}{c}\text { Pre-operative Creatini- } \\
\text { ne }(\mathrm{mg} / \mathrm{ml})\end{array}$ & $\begin{array}{c}\text { Post-operative Creatinine } \\
\text { (mg/ml) }\end{array}$ \\
\hline 1 & Clear Cell & 2 & No & 1.0 & 0.9 \\
2 & Clear Cell & 1 & No & 0.9 & 0.9 \\
3 & Papillary & 1 & No & 0.6 & 0.8 \\
4 & Clear Cell & 1 & No & 0.9 & 1.0 \\
5 & Chromophobic & 1 & No & 0.8 & 0.8 \\
6 & Clear Cell & 3 & No & 1.1 & 1.3 \\
7 & Oncocytoma & - & - & 0.9 & 1.0 \\
8 & Oncocytoma & - & - & 0.7 & 0.8 \\
9 & Clear Cell & 1 & No & 1.1 & 1.1 \\
10 & Clear Cell & 2 & No & 0.8 & 0.8 \\
\hline Mean & & & 0.8 & 0.94 \\
\hline
\end{tabular}

${ }^{*}$ Renal Cell Carcinoma; PS = Upper Pole; $\mathrm{TM}=$ Medium Third; PI = Lower Pole

On the pathological analysis, two lesions had benign etiology (oncocytoma), and among the renal cell carcinomas, six were of clear cells, one papillary, and one chromophobic. The majority of the lesions were of low Fuhrman grade, and no positive surgical margin has been observed in this series (Table 2).

No patient showed significant intraoperative bleeding, with no blood transfusion, as well as urinary fistulas or collections. There was no loss of the renal unit in any patient submitted to surgery. All patients were monitored using the same protocol during a mean follow-up of 36 months (6-72), with no local recurrence or systemic metastatic disease observed.

\section{DISCUSSION}

Anatrophic nephrotomy for handling solid and tumors completely endophytic represents a feasible approach for preservation of the kidney function in all cases, with adequate exposure and safety for tumor resection, as well as collector system closure and hemostasis.
Renal intraparenchymal (endophytic) tumors represent greater technical difficulties for localization and resection and may increase the chances of complications (8). Partial nephrectomy and/or enucleation represent 30\% of the surgical procedures used for renal tumors, with long-term survival similar to radical nephrectomy for the initial stages, with cancer-specific and overall survival of 98\% and $97 \%$ respectively $(1,4,10)$. For tumors $<4 \mathrm{~cm}$, there is no need to remove any additional surgical margin for optimal cancer control. The use of intraoperative ultrasound facilitates the precise identification of the lesion(s), its relation with intra-renal structures and the proximity of the major kidney vessels (9).

There are several definitions of central tumors, of which the best accepted are those of Black et al. (11), which consider that the lesion is completely surrounded by normal renal tissue, and that of Brown et al. (12) that define those with a distance shorter than $5 \mathrm{~mm}$ from the collection system or hilar vessels.

The anatrophic nephrectomy was developed for the treatment of staghorn lithiasis, with 
the opening of the renal parenchyma in the posterior face of the kidney under cold ischemia. Surgery studies targeting surgery for calculi occupying the entire collecting system show an average cold ischemia time varying from 20 to 45 minutes without significant blood loss $(13,14)$. Regarding the loss of renal function, the literature shows that $55 \%$ of the kidney units have their function maintained and just 13\% exhibit a discrete reduction (13). The study of the relative function with DMSA shows an average reduction of 4\% (15). Nohara et al. (15) described their technique for anatrophic partial nephrectomy with selective arterial clamping of the area of the tumor, after an angiography study, with a minor increase of the serum creatinine in the postoperative follow-up.

Nephron-sparing surgery for central but exophytic tumors has shown safety and efficacy compared to peripheral tumors. In a study with 118 patients, the operative and ischemia time, need of the closure of the collection system, and blood transfusion did not exhibit statistically differences (8). However, estimated blood loss was higher in the central tumor group: $220 \mathrm{~mL}(20-3500 \mathrm{~mL})$ against 50 ( 5 to $1500 \mathrm{~mL}$ ) in peripheral tumors. This same study showed a trend towards a higher number of urinomas and urinary fistulas in the central tumor group (8).

The technique presented herein allows a reliable approach, with a clear view of the tumors and their anatomical relations, with low complication rates $(8,6)$. Moreover, it is technically reproductible by the majority of urologists, because of their familiarity with the anatrophic nephrectomy technique used to remove large staghorn calculi. The mean ischemia time of 22.4 minutes is comparable to the time of the partial nephrectomy studies (8) and below the average of those of nephrotomies for treating calculi $(13,14)$.

There is currently a growing use of minimally invasive ablative therapies for small kidney tumors, such as radiofrequency and cryotherapy, providing greater safety and expanding its indications. However, recent studies show a higher failure rate varying from 13\% to 35\% for RFA and 4\% to $6 \%$ for cryoablation $(16,17)$. The main factor for failures on procedures aided by laparoscopy is the endophytic nature of the lesions (8). Besides, there are no series for these types of treatments with patients that are so young such as those presented in this study, and with an adequate follow-up.

The limitations of the present study are represented by the small number of patients, with a median follow-up of 36 months and with no studies of the renal functions of the operated units other than serum creatinine. However, the lesions were safely enucleated and rendered negative margins, with acceptable warm ischemia time.

The nephron-sparing surgery for tumors completely endophytic through anatrophic nephrotomy was safe, with low complication rate and short warm ischemia time. It may be a reliable option when dealing with complex small kidney tumors.

Nowadays, the Urologists have the obligation to try to perform the nephron-sparing surgery in tumors $<7 \mathrm{~cm}$, whenever possible (3-5). In particular, this study wants to reinforce the need for this strategy, since the partial open surgery is mandatory in these cases to avoid loss of renal unit in small $(<4 \mathrm{~cm})$ and asymptomatic tumors.

\section{CONFLICT OF INTEREST}

None declared.

\section{REFERENCES}

1. Riggs SB, Klatte T, Belldegrun AS: Update on partial nephrectomy and novel techniques. Urol Oncol. 2007; 25: 520-2.

2. Dall'Oglio M, Srougi M, Ortiz V, Nesrallah L, Gonçalves PD, Leite KM, et al.: Incidental and symptomatic kidney cancer: pathological features and survival. Rev Assoc Med Bras. 2004; 50: 27-31.

3. Mitchell RE, Gilbert SM, Murphy AM, Olsson CA, Benson MC, McKiernan JM: Partial nephrectomy and radical nephrectomy offer similar cancer outcomes in renal cortical tumors $4 \mathrm{~cm}$ or larger. Urology. 2006; 67: 260-4.

4. Ukimura 0, Haber GP, Remer EM, Gill IS: Laparoscopic partial nephrectomy for incidental stage pT2 or worse tumors. Urology. 2006; 68: 976-82.

5. Leibovich BC, Blute ML, Cheville JC, Lohse CM, Weaver $\mathrm{AL}$, Zincke $\mathrm{H}$ : Nephron sparing surgery for appropriately selected renal cell carcinoma between 4 and $7 \mathrm{~cm}$ results in outcome similar to radical nephrectomy. J Urol. 2004; 171: $1066-70$. 
6. Permpongkosol S, Link RE, Su LM, Romero FR, Bagga HS, Pavlovich CP, et al.: Complications of 2,775 urological laparoscopic procedures: 1993 to 2005. J Urol. 2007; 177: 580-5.

7. Patard JJ, Shvarts O, Lam JS, Pantuck AJ, Kim HL, Ficarra $V$, et al.: Safety and efficacy of partial nephrectomy for all T1 tumors based on an international multicenter experience. J Urol. 2004; 171: 2181-5.

8. Mullerad M, Kastin A, Adusumilli PS, Moskovitz B, Sabo E, Nativ 0: Comparison of nephron-sparing surgery in central versus peripheral renal tumors. Urology. 2005; 65: 467-72.

9. Choyke PL, Pavlovich CP, Daryanani KD, Hewitt SM, Linehan WM, Walther MM: Intraoperative ultrasound during renal parenchymal sparing surgery for hereditary renal cancers: a 10-year experience. J Urol. 2001; 165: 397-400.

10. Herr HW: Partial nephrectomy for unilateral renal carcinoma and a normal contralateral kidney: 10-year followup. J Urol. 1999; 161: 33-4; discussion 34-5.

11. Black P, Filipas D, Fichtner J, Hohenfellner R, Thüroff JW: Nephron sparing surgery for central renal tumors: experience with 33 cases. J Urol. 2000; 163: 737-43.

12. Brown JA, Hubosky SG, Gomella LG, Strup SE: Hand assisted laparoscopic partial nephrectomy for peripheral and central lesions: a review of 30 consecutive cases. J Urol. 2004; 171: 1443-6.

13. Ramakrishnan PA, Al-Bulushi YH, Medhat M, Nair P, Mawali SG, Sampige VP: Modified anatrophic nephrolithotomy: A useful treatment option for complete complex staghorn calculi. Can J Urol. 2006; 13: 3261-70.
14. Morey AF, Nitahara KS, McAninch JW: Modified anatrophic nephrolithotomy for management of staghorn calculi: is renal function preserved? J Urol. 1999; 162: 670-3.

15. Nohara T, Fujita H, Yamamoto K, Kitagawa $Y$, Gabata T, Namiki M: Modified anatrophic partial nephrectomy with selective renal segmental artery clamping to preserve renal function: a preliminary report. Int J Urol. 2008; 15: 961-6.

16. Weight CJ, Kaouk JH, Hegarty NJ, Remer EM, O'Malley CM, Lane BR, et al:: Correlation of radiographic imaging and histopathology following cryoablation and radio frequency ablation for renal tumors. J Urol. 2008; 179: 1277-81; discussion 1281-3.

17. Matin SF, Ahrar K, Cadeddu JA, Gervais DA, McGovern FJ, Zagoria RJ, et al.: Residual and recurrent disease following renal energy ablative therapy: a multi-institutional study. J Urol. 2006; 176: 1973-7.

18. Wright AD, Turk TM, Nagar MS, Phelan MW, Perry KT: Endophytic lesions: a predictor of failure in laparoscopic renal cryoablation. J Endourol. 2007; 21: 1493-6.

Correspondence address Dr. Marcos F. Dall'Oglio Rua Barata Ribeiro, 398, 5․ Andar. Sao Paulo, SP, 01308-000, Brazil. Fax: + 5511 3159-3618

E-mail: marcosdallogliouro@terra.com.br 